\title{
Hyperemesis Gravidarum and Hyperthyroidism
}

\author{
Apra Attri ${ }^{1}$, Priyanka Sharma ${ }^{2}$ \\ ${ }^{1}$ Medical Officer, MGMSC Khaneri, Rampur, HP, India \\ ${ }^{2}$ Medical Officer, Pt. JLNGMC, Chamba, HP, India \\ Corresponding Author: Priyanka Sharma
}

\begin{abstract}
Hyperemesis gravidarum might require hospitalisation in patients, and upto two-thirds of women with hyperemesis gravidarum have transient hyperthyroidism. We undertook a study of pregnant women admitted with no known cause of vomiting. These patients were subjected to tests for TSH, Total $\mathrm{T}_{4}$, and Total $\mathrm{T}_{3}$ hormones to establish hyperthyroidism, and the values of these tests were serially monitored. We studied pregnancy outcomes such as period of gestation, and weight at birth, Apgar score at three and five minutes, and maternal TSH values at birth. The Total $\mathrm{T}_{4}$, Total $\mathrm{T}_{3}$, and TSH levels had normalised by gestational age of 14-16 weeks, and TSH at birth was found to be normal. Birth weight showed only a small deviation. The results suggest that asymptomatic patients with TSH value indicating hyperthyroidism in the first trimester need no further revaluation.
\end{abstract}

Keywords: Hyperemesis gravidarum, pregnancy, hyperthyroidism

\section{INTRODUCTION}

Hyperemesis gravidarum is a condition that presents with severe persistent vomiting mostly during the first trimester of pregnancy, causing the patient to be unable to retain liquids and solids, which might require admission to a hospital and intravenous hydration. Upto two-thirds of women with hyperemesis gravidarum have transient hyperthyroidism ${ }^{1,2}$. The levels of human Chorionic gonadotropin (hCG) is considered a risk factor in its pathogenesis. Thyrotropic action of $h C G$ has been studied ${ }^{3}$, and studies have shown a relationship between $T_{4}$ (Total Thyroxine) levels and peak hCG values during early gestation $^{4,5}$.

Thyroid Stimulating Hormone
(TSH) and hcG are structurally
homologous, as are their receptors, and this forms the basis of cross reactivity.

We undertook a study to evaluate clinical outcome in women with transient hyperthyroidism of hyperemesis gravidarum.

\section{METHODS}

The study was undertaken at MGMSC, Khaneri, Rampur in Himachal Pradesh on women admitted with hyperemesis gravidarum for a period of twelve months. Only the women who went on to have deliveries at the hospital were included in the study. Only the women for whom no other cause for vomiting was found were included in the study. Ultrasound to rule out multiple gestation and molar pregnancy was carried out. These patients were further subjected to routine natal investigations and RFT, LFT, and urine test for ketone bodies. Assessment of thyroid function was performed in these women by performing $\mathrm{T}_{3}, \mathrm{~T}_{4}, \mathrm{TSH}$, and TPO Antibody test. Serial monitoring was done at the gestational age of 6-8 weeks, 1012 weeks, and 14-16 weeks.

Hyperthyroidism was defined as TSH level of lower than $0.6 \mu \mathrm{IU} / \mathrm{mL}$ for the first trimester, and less than $0.37 \mu \mathrm{IU} / \mathrm{mL}$ for the second and third trimester. Total $\mathrm{T}_{4}$ level of more than $10.1 \mu \mathrm{g} / \mathrm{dL}$ was 
considered abnormal for the first trimester, and $10.3 \mu \mathrm{g} / \mathrm{dL}$ in the second trimester. Total $\mathrm{T}_{3}$ was considered abnormal for values greater than $149 \mathrm{ng} / \mathrm{dL}$ for the first trimester, and greater than $169 \mathrm{ng} / \mathrm{dL}$ for second trimester.

The pregnancy outcomes studied included period of gestation, and weight at birth, Apgar score at three and five minutes, and maternal TSH values at birth.

\section{RESULTS}

Over a period of 12 months, 72 women were hospitalised for hyperemesis gravidarum. On undergoing thyroid function testing $47(65.28 \%)$ were identified to have hyperthyroidism. Out of these 47 women, 1 (1.39\%) patient was diagnosed with Grave's Disease, and 46 (63.89\%) with transient hyperthyroidism.

The levels of Thyroid peroxidase antibody (TPO) were considered abnormal above $0.3 \mathrm{U} / \mathrm{mL}$. Out of 47 women with hyperthyroidism, only one case of abnormal TPO was detected, and the patient was a known case of Grave's Disease, hence was excluded from the further study.

The average values for the demographical profile of the patients with transient hyperthyroidism are shown in Table 1. The mean age of the subjects was 24.87 years with a standard deviation of 3.95 years. The maximum gestation at the time of admission was 12 weeks and the mean was 9.60 weeks ( $\sim 9$ weeks +4 days).

The results of the different tests of the women with transient hyperthyroidism are shown in Table 2. The results of AST/ALT were considered abnormal if the values were greater than $80 \mathrm{U} / \mathrm{L}$, whereas bilirubin levels above $2.2 \mathrm{mg} / \mathrm{dL}$ were considered abnormal.

The number of patients with abnormal values of TSH, Total $\mathrm{T}_{3}$, Total $\mathrm{T}_{4}$ are shown in Figure 1. The average values over time for TSH are shown in Figure 2, for Total $\mathrm{T}_{4}$ are shown in Figure 3, and for Total $\mathrm{T}_{3}$ are shown in Figure 4.

The modes of delivery are shown in Table 3. Most women (63.04\%) had vaginal delivery, and only two cases of spontaneous or missed abortion was observed.

The gestational period of women at delivery are shown in Table 4. The two women whose pregnancy resulted in spontaneous or missed abortion are excluded from the results shown. Four cases (9.09\%) of pre-term birth were observed, and the average gestational age at birth was 38 weeks and 4 days, with a standard deviation of 12.67 days.

The birth-weight of the babies is shown in Table 5. The average weight at birth was $2.81 \mathrm{~kg}(\sim 2811 \mathrm{~g})$, with a standard deviation of $220.44 \mathrm{~g}$.

The Apgar scores at birth are shown in Table 6. Apgar score at three minutes ranged from 6 to 8 , while at five minutes were in the range of 8 to 10 .

The results of maternal TSH at birth are shown in Table 7 . The average value was $1.91 \mu \mathrm{IU} / \mathrm{mL}$.

\section{DISCUSSION}

All patients showed normal TSH values at delivery, confirming that they were suffering from transient hyperthyroidism.

The $\mathrm{T}_{4}$ levels had normalised by 1416 weeks, which was similar to the study by Tan et $\mathrm{al}^{6}$. Similar study by Malek et al found that thyroid function to normalise at 20 weeks $^{7}$, whereas Goodwin et al found the values normalised by 18 weeks ${ }^{1}$.

Birth weight shows a small deviation from the mean $(\sim 220 \mathrm{~g})$, and the gestational age at delivery were also similar. This finding is consistent with other studies ${ }^{4}$.

Maternal TSH values had normalised by 14-16 weeks, and were again found to be normal at birth.

The results of this study indicate that if in the first trimester of pregnancy, the TSH values for asymptomatic patients are detected in range that suggests hyperthyroidism, then no further revaluation is required in such cases. 


\section{TABLES AND FIGURES}

Table 1: Profile of patients with transient hyperthyroidism $(\mathrm{n}=46)$

\begin{tabular}{|l|l|}
\hline Characteristics & Value \\
\hline Mean Age (years) & 24.87 (Min: 19, Max: 32) \\
& Standard Deviation: 3.95 \\
\hline Mean Gestation Period (at & 9.60 weeks (Min: 7w+2d, Max: 12) \\
admission) & Standard Deviation: 9.57days \\
\hline Pre-pregnancy BMI & 20.62 (Min: 18.6, Max: 22.5) \\
& Standard Deviation: 1.08 \\
\hline
\end{tabular}

Table 2: Thyroid Antibody Profile

\begin{tabular}{|l|l|}
\hline Test & $\begin{array}{l}\text { Number of Patients } \\
\text { with Abnormal Results }\end{array}$ \\
\hline Abnormal AST or ALT $(>80 \mathrm{U} / \mathrm{L})$ & $10(21.74 \%)$ \\
\hline Abnormal Bilirubin $(>2.2 \mathrm{mg} / \mathrm{dL})$ & $5(10.87 \%)$ \\
\hline
\end{tabular}

Table 3: Pregnancy Outcomes

\begin{tabular}{|l|l|}
\hline Mode of Delivery $(\mathbf{n = 4 6})$ & Number \\
\hline Vaginal Delivery & $29(63.04 \%)$ \\
\hline Caesarean Section & $15(32.61 \%)$ \\
\hline Spontaneous or Missed Abortion & $2(4.35 \%)$ \\
\hline
\end{tabular}

Table 4: Outcomes - Gestational Age at Delivery

\begin{tabular}{|l|l|}
\hline $\begin{array}{l}\text { Gestational } \\
\text { Age Distribution }(\mathbf{n}=\mathbf{4 4})\end{array}$ & $\begin{array}{l}\text { Pre-term }(<36 \text { weeks): 4 }(9.09 \%) \\
\text { Normal Gestation: } 40(90.91 \%)\end{array}$ \\
\hline Average Gestational Age & 38 weeks+4 days \\
\hline Max. Gestational Age & 41 weeks \\
\hline Min. Gestational Age & 33 weeks + 1 day \\
\hline Standard Deviation & 12.67 days \\
\hline
\end{tabular}

Table 5: Outcomes - Birth Weight

\begin{tabular}{|l|l|}
\multicolumn{2}{|c|}{ Table 5: Outcomes - Birth Weight } \\
\hline \multicolumn{2}{|c|}{ Kg } \\
\hline Average Weight & 2.81 \\
\hline Max. Weight & 3.19 \\
\hline Min. Weight & 2.41 \\
\hline Standard Deviation & 0.22 \\
\hline
\end{tabular}

Table 6: Outcomes - Apgar Scores

\begin{tabular}{|l|l|l|}
\hline At 3 minutes $(\mathrm{n}=44)$ & Score & Number of Cases \\
\cline { 2 - 3 } & 6 & $18(41.91 \%)$ \\
\cline { 2 - 3 } & 7 & $17(38.64 \%)$ \\
\cline { 2 - 3 } & 8 & $9(20.45 \%)$ \\
\hline At 5 minutes $(\mathrm{n}=44)$ & Score & Number of Cases \\
\cline { 2 - 3 } & 8 & $13(29.54 \%)$ \\
\cline { 2 - 3 } & 9 & $18(40.91 \%)$ \\
\cline { 2 - 3 } & 10 & $13(29.54 \%)$ \\
\hline
\end{tabular}

Table 7: Outcomes - Maternal TSH Levels at Birth

\begin{tabular}{|l|l|}
\hline \multicolumn{2}{|c|}{ Table 7: Outcomes - Matues $(\boldsymbol{\mu l} \mathbf{U} / \mathbf{m L})$} \\
\hline Average Value & 1.91 \\
\hline Range & $0.47-4.01$ \\
\hline Standard Deviation & 1.096 \\
\hline
\end{tabular}

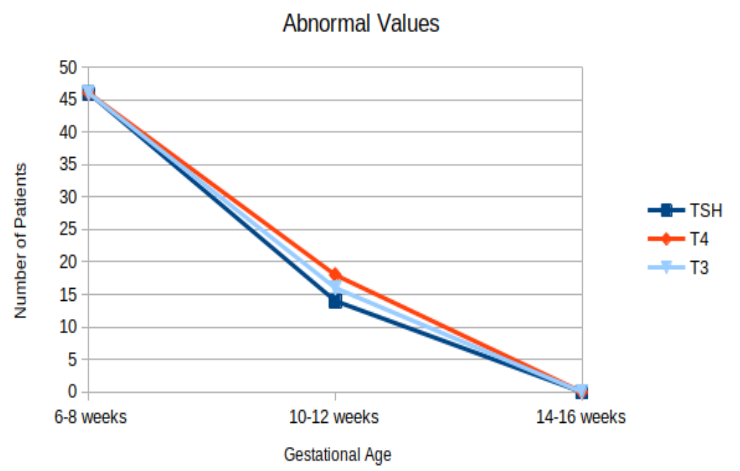

Figure 1: Number of patients with abnormal values of TSH, Total $\mathbf{T}_{4}$, and Total $\mathbf{T}_{3}$
Average Value (TSH)

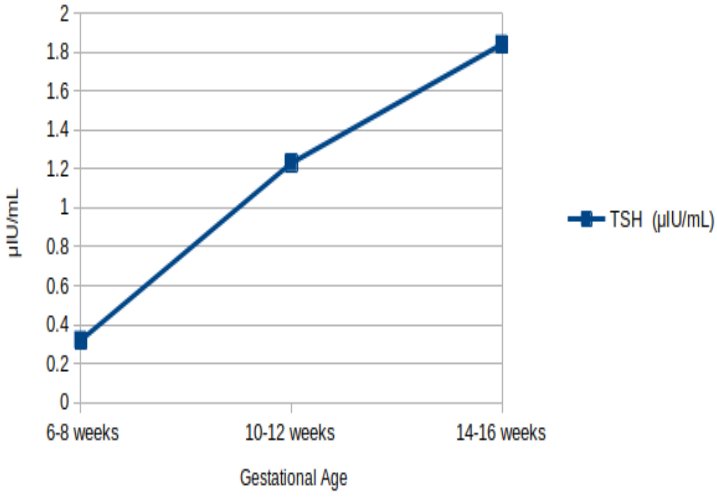

Figure 2: Average values of TSH by gestational age

Average Values (Total T4)

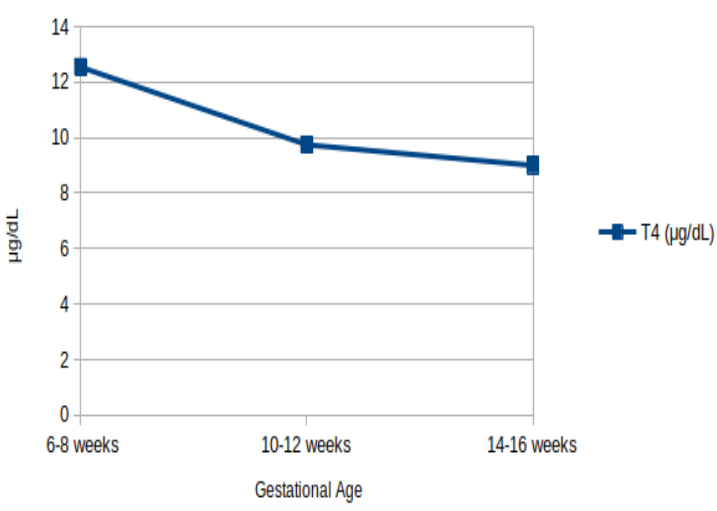

Figure 3: Average values of Total $T_{4}$ by gestational age

Average Values (Total T3)

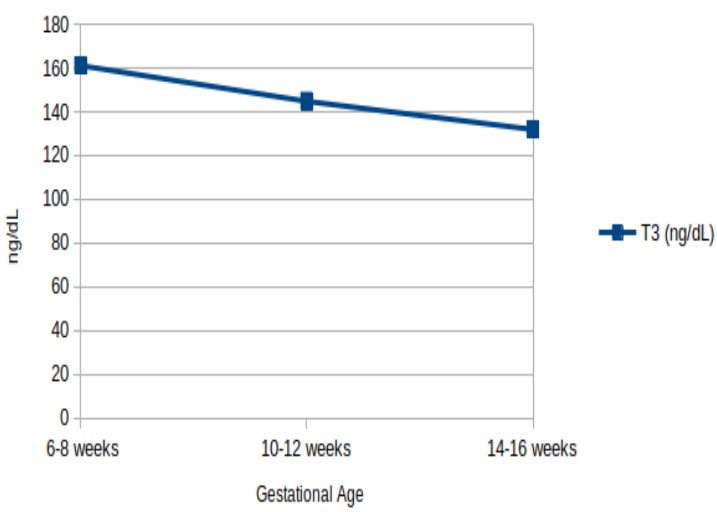

Figure 4: Average values of Total $T_{3}$ by gestational age

Acknowledgement: None

Conflict of Interest: None

Source of Funding: None

Ethical Approval: Approved 


\section{REFERENCES}

1. Goodwin TM, Montro M, Mestman JH. Transient hyperthyroidism and hyperemesis gravidarum: clinical aspects. Am J Obstet Gynecol; 1992. 167:648 - 652

2. Caffrey T. Transient Hyperthyroidism of Hyperemesis Gravidarum: A Sheep in Wolfs Clothing. The Journal of the American Board of Family Practice; 2000. 13 (1) $35-38$

3. Yoshimura M, Hershman JM. Thyrotropic action of human chorionic gonadotropin. Thyroid; 1995. 5:425 - 434

4. Glinoer D., De Nayer P., Bourdoux P., Lemone M., Robyn C., Van Steirteghem A., Kinthaert J., Lejeune B. Regulation of maternal thyroid during pregnancy. J. Clin. Endocrinol Metab; 1990. 71(2):276-87.

5. Kimura M, Amino N, Tamaki H, Ito E, Mitsudat N, Miyai K, and Tanizawat O. Gestational thyrotoxicosis and hyperemesis gravidarum: possible role of hCG with higher stimulating activity. Clinical Endocrinology; 1993. 38, 345-350,

6. Tan, J., Loh, K., Yeo, G., Chee, Y. Transient hyperthyroidism of hyperemesis gravidarum. BJOG: an International Journal of Obstetrics and Gynaecology; 2002 Jun.109(6):683-8.

7. Malek, N., Kalok, A., Hanafiah, Z., Shah, S. \& Ismail, N. Association of transient hyperthyroidism and severity of hyperemesis gravidarum. Hormone Molecular Biology and Clinical Investigation; 2017 Mar 23. 30(3), 20160050.

How to cite this article: Attri A, Sharma P. Hyperemesis gravidarum and hyperthyroidism. Int J Health Sci Res. 2021; 11(9): 75-78. DOI: https://doi.org/10.52403/ijhsr.20210911 